\title{
Morfoanatomia foliar de microorquídeas de Ornithocephalus Hook. e Psygmorchis Dodson \& Dressler
}

\author{
Rayza Carla Lopes Della Colleta ${ }^{1,2}$ e Ivone Vieira da Silva ${ }^{1}$
}

Recebido em 23/05/2007. Aceito em 11/03/2008

\begin{abstract}
RESUMO - (Morfoanatomia foliar de microorquídeas de Ornithocephalus Hook. e Psygmorchis Dodson \& Dressler). Analisou-se a morfoanatomia foliar de Ornithocephalus bicornis Lindl. ex Benth., Ornithocephalus myrticola Lindl., Psygmorchis pusilla (L.) e Psygmorchis glossomystax (Rchb. f.), a fim de identificar caracteres de valor taxonômico e significado ecológico. Folhas expandidas foram coletadas na região de Alta Floresta, MT. As amostras foram incluídas em metacrilato, cortadas em micrótomo de mesa e corados com azul de toluidina. As lâminas foram montadas em resina sintética ou gelatina glicerinada. Epidermes foliares foram dissociadas e testes histoquímicos aplicados. As plantas observadas neste estudo são epífitas, carnosas e não apresentam pseudobulbos. A epiderme é uniestratificada e delgada com exceção de O. bicornis que é espessa, apresentando cutícula delgada e lisa. As espécies estudadas apresentam folhas anfiestomáticas com os estômatos presentes no mesmo nível das células epidérmicas. Os estômatos geralmente são anomocíticos e tetracíticos em $O$. myrticola, P. pusilla e P. glossomystax. Em O. bicornis ocorrem tetracítico, anisocítico e actinocítico. As células-guarda são de paredes periclinais espessas e as câmaras subestomática são pequenas, exceto em $P$. pusilla. Com exceção de O. bicornis, o mesofilo das espécies é heterogêneo, sendo constituído de diferentes tipos de parênquima. Os feixes vasculares são colaterais. As espécies foram consideradas mesófilas.
\end{abstract}

Palavras-chave: microorquídeas, morfoanatomia foliar, Orchidaceae

\begin{abstract}
Leaf anatomy of micro-orchids of Ornithocephalus Hook. and Psygmorchis Dodson \& Dressler). Leaf anatomy of O. bicornis Lindl. ex Benth., O. myrticola Lindl., P. pusilla (L.) and P. glossomystax (Rchb. f.) was analyzed to identify valuable taxonomic and ecological traits. Expanded leaves were collected in the Alta Floresta, Mato Grosso State, region. Leaf samples embedded in methacrylate were cut with a table microtome and stained with toluidine blue. Slides were mounted in synthetic resin or in glycerin gelatin. Leaf tissues were dissociated and histochemical tests applied. Plants observed in this study are succulent epiphytes without pseudobulbs. The epidermis is uniseriate and thin, with the exception of $O$. bicornis which has a relatively thick epidermis, and a thin, smooth cuticle. The species have amphistomatic leaves and the stomata are at the same level as the epidermal cells. Stomata are generally anomocytic and tetracytic in $O$. myrticola, $P$. pusilla and $P$. glossomystax. O. bicornis has tetracytic, anisocytic and actinocytic stomata. Guard cells have thick periclinal walls and small substomatic chambers, except in $P$. pusilla. With the exception of $O$. bicornis, species have heterogeneous mesophyll with different types of parenchyma. All vascular bundles are collateral. The species are mesophytic.
\end{abstract}

Key words: micro-orchids, leaf morpho-anatomy, Orchidaceae

\section{Introdução}

Segundo Englert (2000), as orquídeas compreendem uma das famílias mais numerosas do mundo das monocotiledôneas, sendo constituída de 500 a 800 gêneros e entre 20.000 a 30.000 espécies. As orquídeas brasileiras incluem 191 gêneros, e aproximadamente 2.300 espécies, sendo produzidas outros tantos híbridos, por cruzamento de formas espontânea e cultivada (Suttleworth 1997).

Orquídeas são plantas herbáceas perenes, algumas vezes trepadeiras ou arbustos, mas na sua maioria epífitas, podendo também ser rupícolas ou terrestres, raramente semi-aquáticas ou subterrâneas (Cronquist
1988). Podem crescer em climas frios, quentes e em regiões temperadas, sendo encontradas em maior abundância, não só em número como em variedade, nas regiões tropicais (Englert 2000). Quanto ao tamanho, há orquídeas com as mais variadas dimensões, desde plantas extremamente pequenas, como as microorquídeas, até plantas com mais de três metros de altura, sendo capazes de produzir hastes florais de comprimento superior a quatro metros (Suttleworth 1997).

Segundo Royal Botanic Gardens, Kew (2007) Ornithocephalus Hook. compreende 47 espécies e Psygmorchis Dodson \& Dressler compreende sete espécies, os gêneros objetos do presente estudo apresentam hábito epifítico e fazem parte da subfamília

\footnotetext{
1 Universidade do Estado de Mato Grosso, Departamento de Ciências Biológicas, Rod. MT 208, km 146, Jardim Tropical, 78580-000 Campus de Alta Floresta, MT, Brasil

2 Autor para correspondência: rayza_colleta@hotmail.com
} 
Epidendroideae, tribo Maxillarieae, sendo o primeiro pertencente a Ornithocephalinae e o segundo, Oncidiinae (Orchidaceae Brasilienses 2006).

A morfoanatomia é peça chave no estudo de caracterização das espécies (Dressler 1993). Quando a morfologia, principalmente a vegetativa, é muito similar, nas espécies, a anatomia se torna uma ferramenta eficiente para diferenciação das mesmas. Embora a anatomia não seja tão acessível quanto a morfologia externa, pesquisadores têm-se dedicado na busca de novos caracteres que auxiliem na taxonomia (Mayr 1989).

A comparação anatômica tem provado ser útil em numerosos estudos taxonômicos (Carlquist 1961), porém, é necessário entender a variação dos caracteres dentro de um indivíduo, espécie ou grupo de táxons relacionados, que podem ser qualitativos ou quantitativos. As folhas são órgãos altamente plásticos e isto pode ser específico para as espécies, gêneros ou famílias. Numerosos caracteres anatômicos, tais como características da epiderme, inclusões minerais e estruturas secretoras, tem provado ser de valor diagnóstico em diferentes linhagens (Dickison 2000).

Segundo Segatto et al. (2004), os estudos anatômicos assumem maior importância quando associados aos aspectos ecológicos, fisiológicos e taxonômicos.

O presente estudo teve como objetivo caracterizar anatomicamente as folhas das espécies $O$. bicornis, $O$. myrticola, $P$. pusilla e $P$. glossomystax, a fim de identificar possíveis estratégias adaptativas, semelhanças e/ou diferenças quanto a morfologia e a anatomia dos gêneros, além de fornecer novos dados para os estudos de taxonomia e sistemática.

\section{Material e métodos}

Para os estudos anatômicos e histoquímicos, três folhas totalmente expandidas de O. bicornis, $O$. myrticola, $P$. pusilla e $P$. glossomystax, foram coletadas na Chácara Recanto das Orquídeas, localizada na Perimetral Auxiliar Oeste s.n. entre as coordenadas $56^{\circ} 05^{\prime} 44.5^{\prime \prime} \mathrm{W}$ e $09^{\circ} 52^{\prime} 34,2^{\prime \prime} \mathrm{S}$ no município de Alta Floresta. As coletas foram realizadas no mês de maio, junho e julho/2006, as folhas foram fixadas em $\mathrm{FAA}_{50}$ (Johansen 1940) e posteriormente analisadas.

Porções medianas da lâmina foliar (zona da nervura mediana e bordo) foram isoladas e incluídas em metacrilato. Os blocos foram cortados transversal e longitudinalmente em micrótomo rotativo. Os cortes, com espessura de $8 \mu \mathrm{m}$, foram corados com azul de toluidina (O'Brien \& McCully 1981) e as lâminas montadas em resina (Permount).

Epidermes foliares foram dissociadas (Johansen 1940), coradas em azul de astra e fucsina básica
(Roeser 1972 apud Kraus \& Arduin 1997) e montadas com gelatina glicerinada, também foram feitas seções transversais na região mediana, com o auxílio de lâminas de barbear, utilizando-se de material fixado. Para os testes histoquímicos, foram empregados reagente de lugol (Bücherl 1962) para identificar o amido, solução de fucsina para lignina e azul de astra para celulose.

Os registros foram realizados através de ilustrações e fotos dos aspectos mais característicos das espécies e das seções anatômicas. Para a caracterização morfológica foliar externa houve mensuração de comprimento, largura e espessura.

Para a determinação do índice estomático foram feitos cortes paradérmicos nas superfícies adaxial e abaxial da folha. Em seguida foram contadas as células estomáticas e células totais da epiderme em 10 campos aleatórios. Calculou-se o índice estomático utilizando a fórmula: $\mathrm{Si}=\{[\mathrm{Sn} /(\mathrm{Sn}+\mathrm{Em})] \times 100\}$, onde: $\mathrm{Si}=$ índice estomático, $\mathrm{Sn}=$ número de estômatos e $\mathrm{Em}=$ número de células epidérmicas, segundo Cutter (1986).

\section{Resultados}

As espécies estudadas não apresentam pseudobulbos e a característica marcante nestes gêneros é a disposição das folhas em forma de leque. As folhas são glabras, possuem coloração verde amarelada e textura carnosa, as margens são inteiras e lisas e o ápice agudo (Fig. 1-4).

Conforme observado, O. bicornis possui a folha mais comprida, larga e espessa, comparado a O. myrticola. $P$. pusilla possui a folha mais comprida, larga e delgada com relação à $P$. glossomystax. Comparando os dois gêneros temos que Psygmorchis possui folhas mais estreitas e delgadas.

Ornithocephalus bicornis (Fig. 1), apresenta folhas com dimensões de $6,233 \mathrm{~cm}$ de comprimento, $0,944 \mathrm{~cm}$ de largura e $0,130 \mathrm{~cm}$ de espessura. O. myrticola (Fig. 2) possui em média $3,630 \mathrm{~cm}$ de comprimento, $0,883 \mathrm{~cm}$ de largura, e 0,219 $\mathrm{cm}$ de espessura.

Psygmorchis pusilla (Fig. 3) dispõe de folhas de $3,125 \mathrm{~cm}$ de comprimento, $0,533 \mathrm{~cm}$ de largura e $0,090 \mathrm{~cm}$ de espessura. P. glossomystax (Fig. 4) tem $2,833 \mathrm{~cm}$ de comprimento, $0,375 \mathrm{~cm}$ de largura e $0,051 \mathrm{~cm}$ de espessura.

As células epidérmicas são recobertas por cutícula (Fig. 5), de espessura delgada e lisa em todas as espécies, tanto na face abaxial quanto na adaxial (Fig. 6). Em vista frontal, O. bicornis e $O$. myrticola apresentam contorno de parede reta.

A epiderme é uniestratificada (Fig. 6-8) e a parede das células epidérmicas apresenta-se como delgada em todas as espécies (Fig. 5-10), sendo papilosa em 
$O$. myrticola. Outro aspecto a ser ressaltado nas células epidérmicas é a presença de cloroplastos.

As folhas estudadas são anfiestomáticas (Fig. 6). As células-guarda têm forma reniforme e assim como os estômatos localizam-se no mesmo nível das demais células epidérmicas, contudo, projeções cuticulares salientes formam cristas (Fig. 8) sobre o poro, tornando-o obliterado, essas projeções cuticulares não ocorrem em $O$. myrticola.

As células-guarda possuem paredes celulares periclinais espessas (Fig. 10), as câmaras subestomática são pequenas, pouco volumosas (Fig. 6, 8), com exceção de $P$. pusilla. Os estômatos em $O$. myrticola, $P$. pusilla e $P$. glossomystax são predominantemente anomocíticos e tetracíticos (Fig. 14); em O. bicornis ocorrem actinocíticos (Fig. 11), tetracíticos e anisocítico (Fig. 12). O. bicornis, O. myrticola, P. pusilla e $P$. glossomystax apresentam índice estomático com valores baixos. Entre as espécies estudadas, apesar da quantidade de células epidérmicas variarem de 43 a 102, o número de estômatos parece constante. Tricomas glandulares ou tectores não foram presenciados em nenhuma das superfícies da folha.

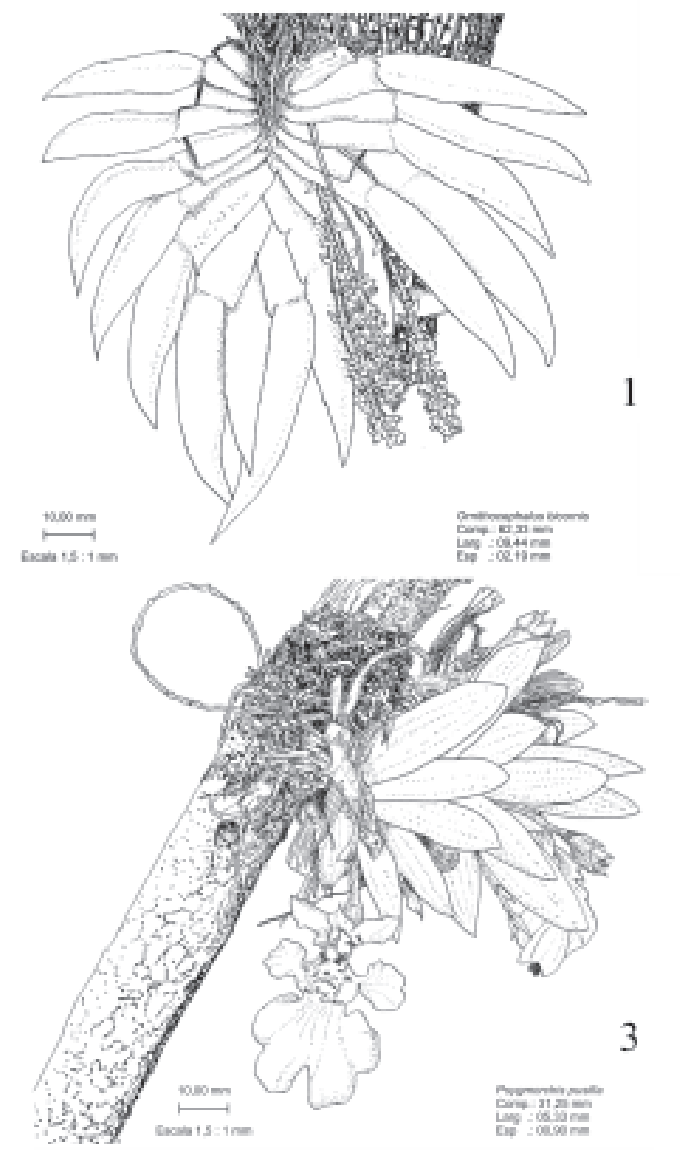

O mesofilo das espécies estudadas, com exceção da $O$. bicornis, é heterogêneo, sendo constituído de diferentes tipos de parênquimas, idioblastos, e outros compostos. Não foram observados hipoderme e grupos de fibras.

O mesofilo homogêneo ocorre apenas na espécie O. bicornis, possuindo células de parede espessadas (Fig. 15). Em O. myrticola ocorrem parênquima clorofiliano e parênquima aqüífero. Psygmorchis pusilla apresenta parênquima clorofiliano e células volumosas no centro (Fig. 16-17). Psygmorchis glossomystax possui parênquima clorofiliano envolvendo toda a superfície da lâmina foliar (Fig. 18) e no centro células mais volumosas (Fig. 19).

Idioblastos contendo ráfides (Fig. 20-21) e drusas de oxalato de cálcio são visualizados em ambas as faces, distribuindo-se aleatoriamente no mesofilo. Em seções longitudinais, esses idioblastos são bastante alongados e as ráfides estão agrupadas (Fig. 21), geralmente orientadas paralelamente ao eixo longitudinal da folha, próximos a epiderme. Amido (Fig. 16, 22) foi evidenciado pelo teste de lugol, nas células do parênquima clorofiliano, especialmente nas células próximas aos feixes vasculares.

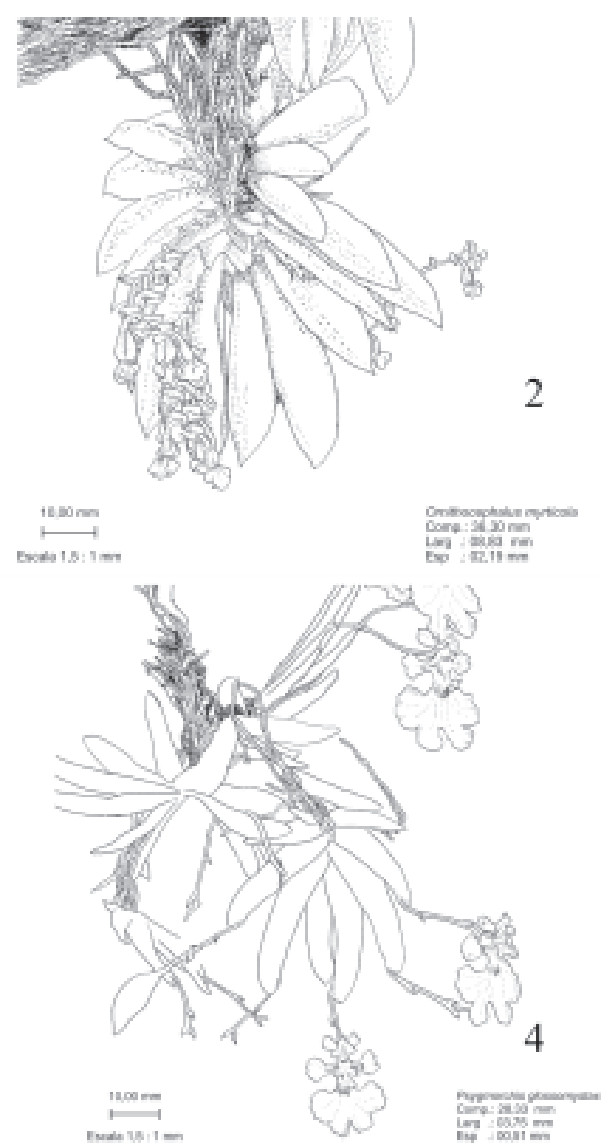

Figuras 1-4. Aspecto geral das espécies de microorquídeas estudas. 1. Ornithocephalus bicornis Lindl. ex Benth. 2. Ornithocephalus myrticola Lindl. 3. Psygmorchis pusilla (L.). 4. Psygmorchis glossomystax (Rchb. f.). 
O sistema vascular das espécies analisadas é constituído por feixes colaterais (Fig. 23-25), com disposição alternada. Psygmochis glossomystax e P. pusilla (Fig. 17) apresentam disposição periférica, ocorrendo um feixe maior na região central, envolvido por células parenquimáticas de parede espessa. Em O. myrticola essa mesma característica é evidenciada sendo os feixes envoltos por células parenquimáticas de parede espessa (Fig. 24). Já em O. bicornis não se observa essa diferença de tamanho entre os feixes, que se encontram envolvidos por células radiadas.

\section{Discussão}

Segundo Withner et al. (1974) o padrão de espessamento da cutícula em geral é determinado pela exposição ao sol, sendo que as folhas mais expostas tendem a exibir uma cutícula mais espessa em ambas as faces. Acredita-se que a temperatura, o solo, a umidade atmosférica e a altitude influenciam no espessamento da cutícula (Esau 1960; Withner et al. 1974; Sinclair 1990; Fahn 1990; Oliveira \& Sajo 1999). As espécies estudadas ocorrem em lugares sombreados sendo recobertas por

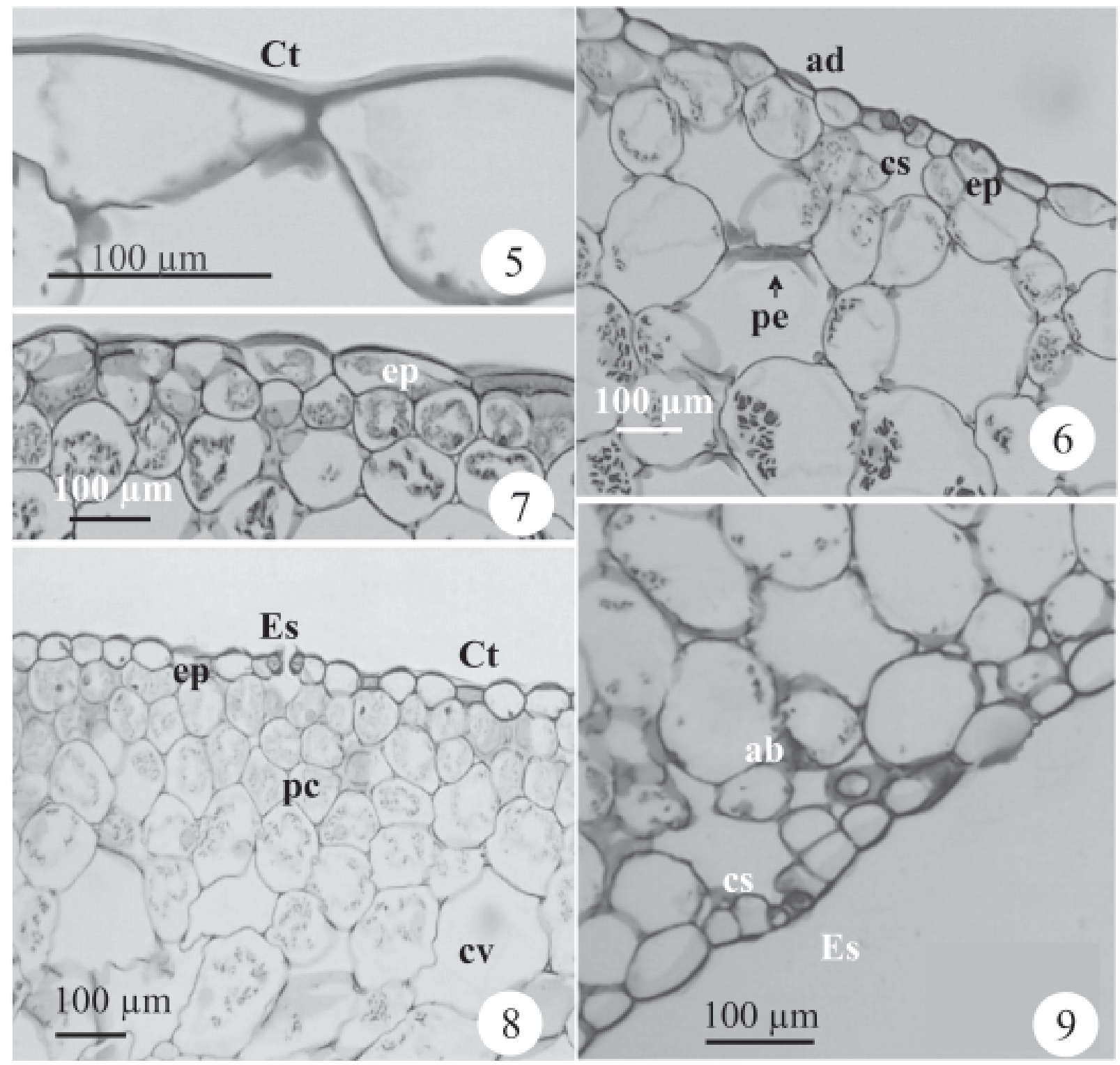

Figuras 5-9. Seções transversais da lâmina foliar de Orchidaceae. 5-6. Ornithocephalus bicornis Lindl. ex Benth. destacando a epiderme adaxial e cutícula. 7. Psygmorchis pusilla (L.). 8. Psygmorchis glossomystax. 9. Ornithocephalus myrticola Lindl. Abreviações: cutícula (Ct), epiderme (ep), adaxial (ad), abaxial (ab), câmara subestomática (cs), células de parede espessa (pe), células volumosas (cv), parênquima clorofiliano (pc) e estômatos (Es). 
cutícula delgada, observação que está de acordo com o sugerido por Withner et al. (1974). Dunn et al. (1965) registraram a ocorrência de cutícula enrugada na maioria das espécies de ambiente xérico e de cutícula lisa para espécies mesófitas ou hidrófitas.

Com relação ao tamanho das células epidérmicas, P. pusilla apresenta células de maior dimensão. Estas células parecem estar relacionadas com reserva de água (Kurzweil et al. 1995).

Nas espécies estudadas a epiderme é uniestratificada, o que parece ser padrão entre as Orchidaceae (Campos Leite 1986). Segundo Sinclair (1990) o espessamento das paredes celulares também parece contribuir para a resistência das folhas à perda de água. Fahn (1990)

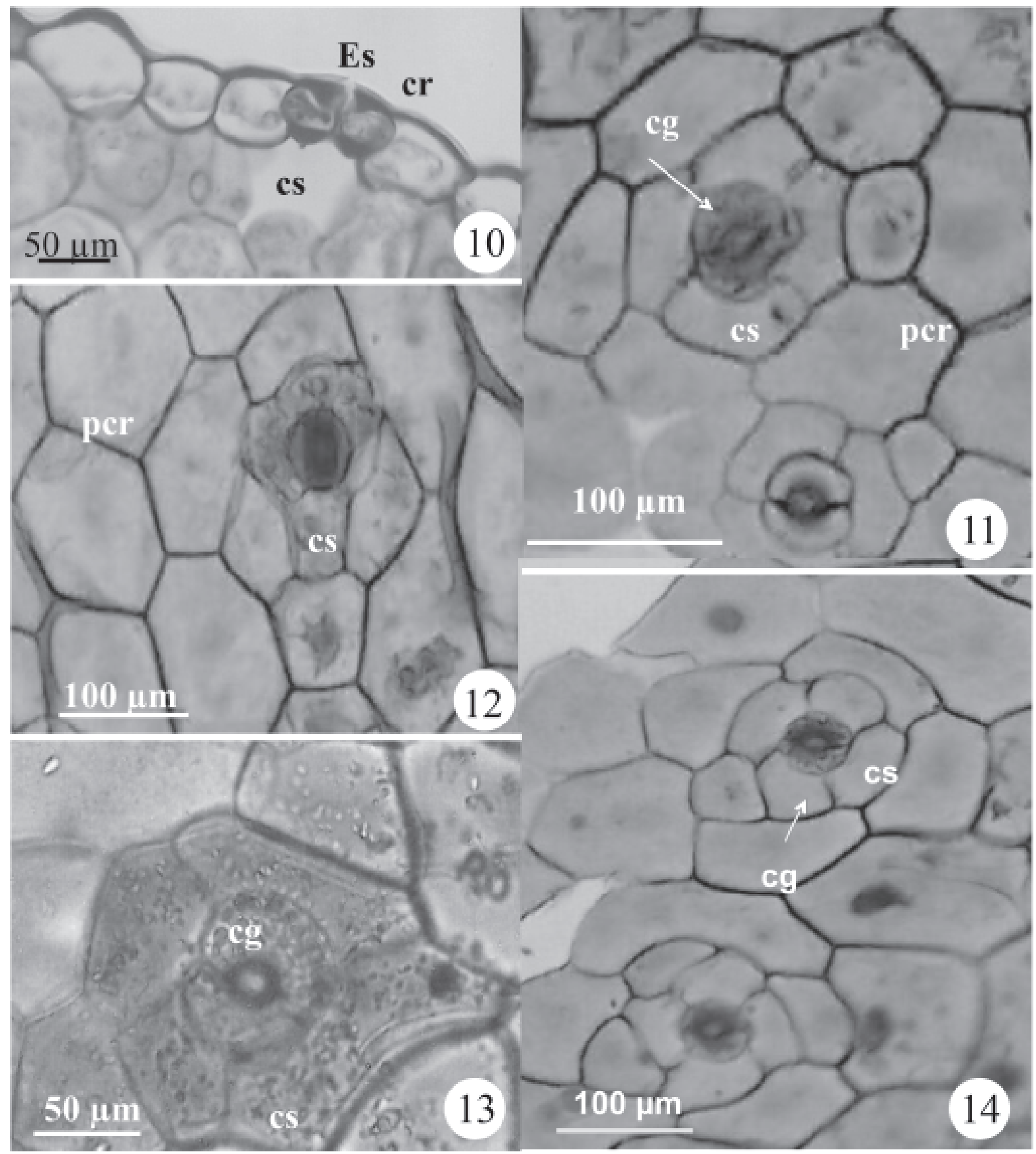

Figuras 10-14. Aspectos anatômicos da lâmina foliar de Orchidaceae. 10. Corte transversal da lâmina foliar de Ornithocephalus bicornis Lindl. ex Benth. 11-12. Corte paradérmico de Ornithocephalus bicornis Lindl. ex Benth., evidenciando estômatos actinocítico e anisocítico. 13. Corte paradérmico de Psygmorchis pusilla (L.) evidenciando estômato tetracítico. 14. Corte paradérmico de Ornithocephalus myrticola Lindl. evidenciando estômato tetracítico. Abreviações: estômato (Es), crista (cr), célula-guarda (cg) e célula subsidiária (cs). 

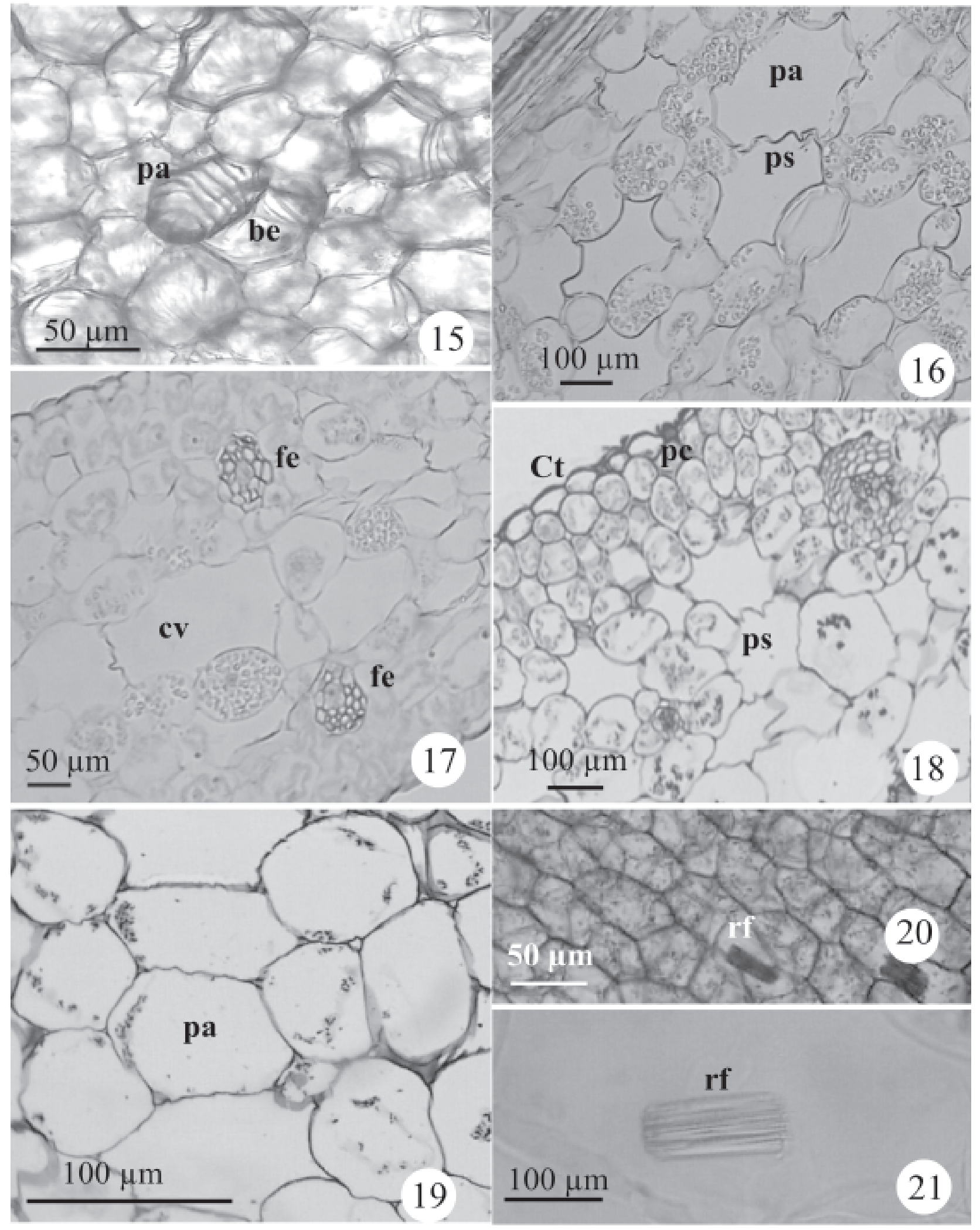

Figuras 15-21. Aspectos anatômicos do mesofilo na região mediana da lâmina foliar de Orchidaceae. 15. Ornithocephalus myrticola Lindl. 16. Psygmorchis pusilla (L.). 17. Cortes transversais evidenciando o mesofilo e feixe vascular de espécime Psygmorchis pusilla (L.). 18. Corte da lâmina foliar de Psygmorchis glossomystax (Rchb. f.) mostrando a região da epiderme em vista frontal e parte do mesofilo. 19-20. Epiderme em vista frontal de Psygmorchis glossomystax (Rchb. f.). 21. Psygmorchis pusilla (L.). Abreviações: cutícula (Ct), parênquima aqüífero (pa), parede sinuosa (ps), feixe vascular (fe), parênquima clorofiliano (pc), célula volumosa (cv) e ráfides (rf). 
também menciona o aumento da espessura das paredes, referindo-o como adaptação a ambientes secos.

Papilas ocorrem em O. myrticola. Uphof (1962) sugere que as células papilosas da epiderme agem como lentes, convergindo os raios luminosos para o interior do mesofilo, conforme demonstrado por Bone et al. (1985). Ainda segundo o mesmo autor, a intensa pluviosidade nas florestas tropicais, aliada a projeção acima do nível da água de suas extremidades, possibilita o formação de um filme de água sobre sua superfície, possibilitando a continuidade do processo de absorção de energia luminosa, além da captação de estímulos luminosos.

A ocorrência de cloroplastos em células epidérmicas de Orchidaceae como visto nas espécies em estudo são comuns em hidrófitas, sendo citada por Metcalfe et al. (1983). Withner et al. (1974) e Silva et al. (2006) também registram cloroplastos em Orchidaceae, que representam um importante acréscimo na produtividade destas plantas, pelo maior volume de tecidos fotossintetizantes ativos, constituindo assim uma vantagem seletiva.

O caráter hipoestomático parece ser o padrão para a maioria das Orchidaceae (Withner et al. 1974; Singh 1981; Oliveira \& Sajo 1999; Zanengo-Godoy \& Costa 2003; Stern et al. 2004; Silva et al. 2006), sendo algumas poucas espécies anfiestomáticas. De acordo com Fahn \& Cutler (1992) folhas hipoestomáticas são mais comuns em plantas de regiões úmidas do que secas, predominando folhas anfiestomáticas em regiões secas. Segundo Rasmussen (1987), os estômatos e célulasguarda com paredes periclinais espessas e lignificadas em Orchidaceae raramente são aprofundados.

Nas espécies estudadas o carater hipoestomático, parece não estar envolvido como resposta a um estresse ambiental, mas como um fator endógeno da planta. Células guarda com paredes periclinais espessas e lignificadas e a presença projeções cuticulares conforme,

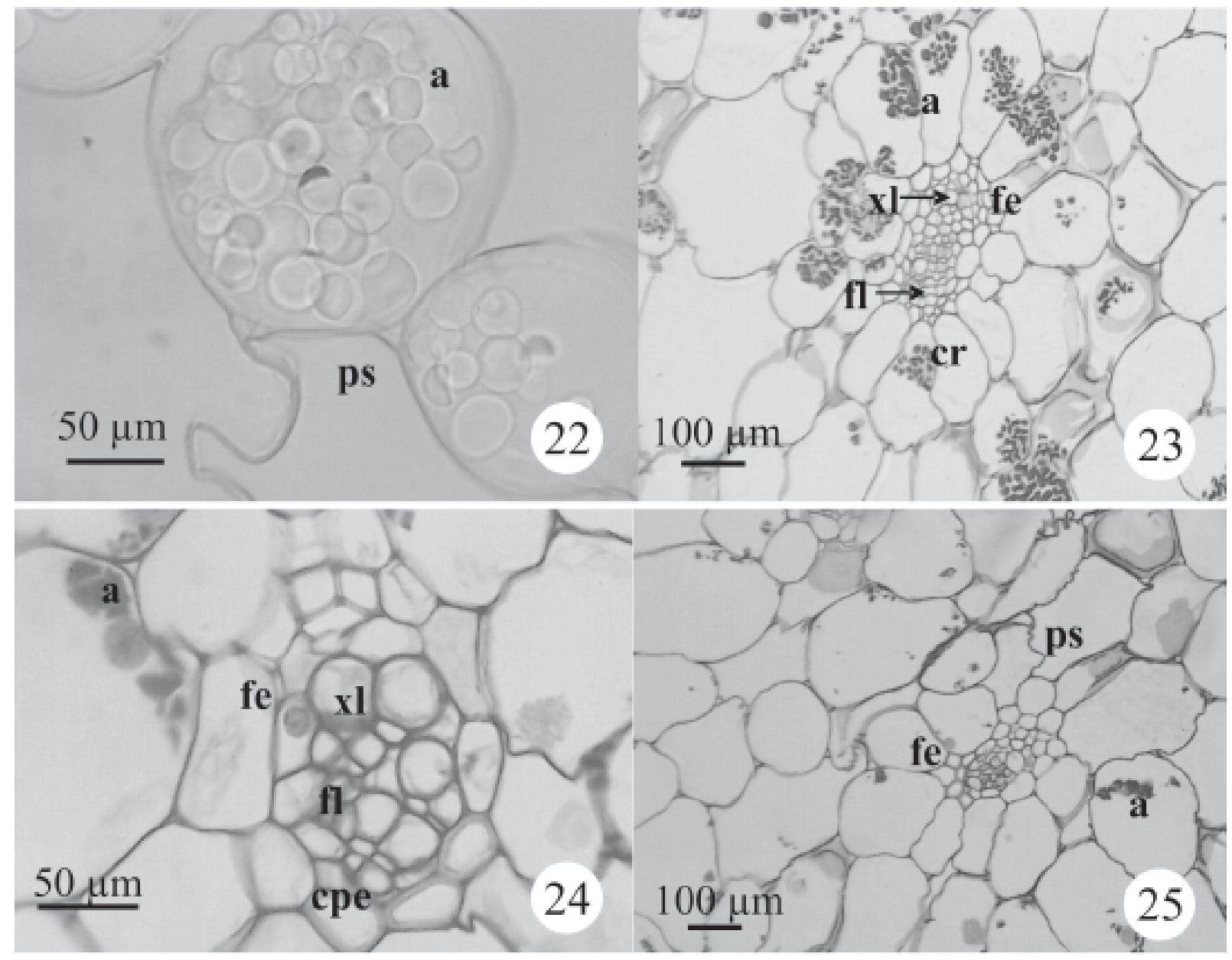

Figuras 22-25. Aspectos anatômicos da região mediana da lâmina foliar de Orchidaceae. 22. Psygmorchis pusilla (L.) 23. Corte transversal de Ornithocephalus bicornis Lindl. ex Benth. evidenciando o sistema vascular. 24 e 25. Cortes de Ornithocephalus myrticola e Lindl. evidenciando o feixe vascular. Abreviações: amido (a), xilema (xl), floema (fl), células radiadas (cr), células de parede espessada (cpe), parede sinuosa (ps) e feixe vascular (fe). 
observado para as espécies analisadas e também por outros autores (Zanengo-Godoy \& Costa 2003; Stern et al. 2004; Silva et al. 2006) é considerada como uma característica xeromórfica. Segundo Rasmussen (1987), as paredes periclinais, espessas e lignificadas das cálulas guarda, constituem um marco rígido e indeformável que age como se fosse a parte rígida de um fole.

A ocorrência de estômatos anomocíticos, tetracíticos, actinocíticos e anisocíticos está de acordo com a literatura para Orchidaceae (Zanengo-Godoy \& Costa 2003; Silva et al. 2006). Com relação ao índice estomático existem na literatura poucas referências para espécies de Orchidaceae. Os índices encontrados por Singh \& Singh (1974 apud Sinclair 1990), varia entre 2,0 a 17,0, mostrando que para as espécies em estudo, o índice estomático é baixo.

A densidade de estômatos constitui-se em um fator bastante variável, em virtude de estar relacionada às condições do ambiente (Eames \& Mc Daniels 1953; Esau 1960; Wilkinson 1979). Sinclair (1990) considera o número de estômatos por unidade de área como um fator útil para relacionar as espécies com a sua resistência à seca. Isto porque a densidade aumenta de acordo com o estresse hídrico das folhas e, em uma planta, as folhas podem ter diferentes níveis de estresse. Lleras (1977) afirma que quanto mais xerofíticas as condições, maior a freqüência estomática por unidade de área, o que permite troca de gases mais eficiente nos períodos em que a umidade relativa é alta, quando o perigo de desidratação excessiva é mínimo.

A ocorrência de mesofilo homogêneo, observada nas espécies investigadas, ocorre na maioria das espécies de Orchidaceae (Bonates 1993; Stern et al. 1993; Pridgeon 1994; Oliveira \& Sajo 1999; Stern et al. 2004). Hipoderme e grupos de fibras ao redor dos feixes vasculares não foram encontrados nas espécies analisadas. Sua ausência também foi relatado por Silva et al. (2006) e Stern (1997), ao estudarem Habenaria.

Parênquima aqüífero ocorreu nas espécies $O$. myrticola, $P$. pusilla e $P$. glossomystax, conferindo à folha o aspecto de suculência. A presença de parênquimas clorofiliano e aqüífero diferenciados é indício de que as espécies apresentam metabolismo CAM (Loeschen et al. 1993), que se constitui em uma adaptação à ambientes sujeitos a desidratação, devido à abertura estomática preferencialmente a noite, com consequiências positivas para a economia hídrica.

Foram visualizados cristais, como ráfides e drusas, comumente documentado para as Orchidaceae (Pridgeon 1982; Pridgeon \& Stern 1982; Bonates 1993; Stern et al. 1993; Pridgeon 1994; Oliveira \& Sajo 1999; ZanengoGodoy \& Costa 2003; Stern et al. 2004; Silva et al. 2006) e acredita-se que o oxalato de cálcio contribua para tornar as plantas menos palatáveis aos animais (Mauseth 1995). Bonates (1993) encontrou idioblastos com ráfides em Encyclia calamaria, provavelmente relacionados ao balanço iônico e osmoregulação da planta. Feixes vasculares colaterais são também bastante comuns em Orchidaceae (Pridgeon 1982; Pridgeon \& Stern 1982; Bonates 1993; Stern et al. 1993; Pridgeon 1994; Stern 1997; Oliveira \& Sajo 1999; Zanengo-Godoy \& Costa 2003; Stern et al. 2004; Silva et al. 2006).

A presença de amido e gotículas lipídicas, não obstante sua larga ocorrência como conteúdos celulares, ainda não são comumente mencionados em trabalhos sobre a anatomia foliar das Orchidaceae, embora já documentado por Silva et al. (2006)

Avaliando-se a morfologia e a anatomia foliar de $O$. bicornis, O. myrticola, $P$. pusilla e $P$. glossomystax, verifica-se que as folhas são bem parecidas. Dentre os caracteres que as diferenciam e contribuem para a separação destas espécies estão a presença de um mesofilo homogêneo com células de paredes espessadas em $O$. bicornis, câmara subestomática volumosa em P. pusilla e diferença aparente na disposição e tamanho dos feixes vasculares.

A presença de folhas suculentas, anfiestomáticas, estômatos protegidos por projeções e com poros obliterados, células de paredes espessas no mesofilo homogêneo de $O$. bicornis poderiam ser levados em consideração para classificar as espécies como xerófilas; entretanto, as espécies estudadas vivem em ambiente sombreado e úmido, o que leva a crer que se tratam de estratégias adaptativas ao hábito epifítico, considerando-se dessa forma as espécies estudadas como mesófilas.

\section{Referências}

Bonates, L.M.C. 1993. Estudos ecofisiológicos de Orchidaceae da Amazônia, II. Anatomia ecológica foliar de espécies com metabolismo CAM de uma campina da Amazônia Central. Acta Amazonica 23: 315-348.

Bone, R.A.; Lee, D.W. \& Norman, J.M. 1985. Epidermal cells functioning as lenses in leaves of tropical rain-forest shade plants. Applied Optics 24: 1408-1412.

Bücherl, W. 1962. Técnica Microscópica. São Paulo, Polígono.

Campos Leite, V.M. \& Oliveira, P.L. 1987. Morfo-anatomia foliar de Cattleya intermedia (Orchidaceae). Napaea 2: 1-10.

Carlquist, S. 1961. Comparative Plant Anatomy. New York, Holt, Rinehart and Winston.

Cronquist, A. 1988. The Evolution and Classification of Flowering Plants. $2^{\text {nd }}$ ed. New York, The New York Botanical Garden.

Cutter, E.G. 1986. Anatomia vegetal. 2 ed. São Paulo, Roca.

Dickison, W.C. 2000. Integrative Plant Anatomy. San Diego, Harcourt Academic Press.

Dressler, R.L. 1993. Phylogeny and Classification of the Orchid Family. Cambridge, Cambridge University Press.

Dunn, D.B.; Sharma, G.K. \& Carpbell, C.C. 1965. Stomatal patterns of dicotyledons and monocotyledons. Asmerican Midlland Naturalist 74: 185-195. 
Eames, A.J. \& Mac Daniels, L.H. 1953. An introduction to Plant Anatomy. $2^{\text {nd }}$ ed. New York, London Inc., McGraw-Hill Book.

Englert, S.I. 2000. Orquídeas e Bromélias: manual prático de cultivo. Guaíba, Agropecuária.

Esau, K. 1960. Plant Anatomy. $2^{\text {nd }}$ ed. Tokyo, Toppan Printing.

Fahn, A. 1990. Plant Anatomy. $4^{\text {th }}$ ed. Oxford, Pergamon Press.

Fahn, A. \& Cutler, D.F. 1992. Xerophytes. Pp. 87-98. In: Spez (ed.). Encyclopedia of Plant Anatomy. Berlin, Gebrüder Borntraeger.

Johansen, D.A. 1940. Plant Microtechnique. New York, McGrawHill Book.

Kraus, J.E. \& Arduin, M. 1997. Manual Básico de Métodos em Morfologia Vegetal. Rio de Janeiro, EDUR (Editora Universidade Rural).

Kurzweil, H.; Linder, H.P.; Stern, W.L. \& Pridgeon, A.M. 1995. Comparative vegetative anatomy and classification of Diseae (Orchidaceae). Botanical Journal of the Linnean Society 117: $171-220$

Lleras, E. 1977. Differences in stomatal number per unit area within the same species under different micro-environmental conditions: a working hypothesis. Acta Amazonica 7: 473-476.

Loeschen, V.S.; Martin, C.E.; Smith, M.\& Eder, S.L. 1993. Leaf anatomy and $\mathrm{CO}_{2}$ recycling during crassulacean acid metabolism in twelve epiphytic epecies of Tillandsia (Bromeliaceae). International Journal of Plant Sciences 154: 100-106.

Mauseth, J.D. 1995. Botany: an introduction to plant biology. $2^{\text {nd }}$ ed. London, Saunders College Publishing.

Mayr, E. 1989. O desenvolvimento do pensamento biológico: diversidade, evolução e herança. Brasília, EDUNB (Editora Universidade de Brasília).

Metcalfe, C.R. \& Chalk, L. 1983. Anatomy of the Dicotyledons. Wood Structure and Conclusion of the General Introduction. $2^{\text {nd }}$ ed. Oxford, Clarendon Press.

O'Brien, T.P. \& Mc Cully, M.E. 1981. The Study of Plant Structure: Principles and Selected Methods. Melbourne, Termarcarphi PTY.

Oliveira, V.C. \& Sajo, M.G. 1999. Anatomia foliar de espécies epífitas de Orchidaceae. Revista Brasileira de Botânica 22: 365-374.

Orchidaceae Brasiliensis. Gêneros brasileiros. Disponível em: $<$ http://www.dalholl.hpg.ig.com.br/generos/brasileiros.html>. (Acesso em: 1/03/2007).

Pridgeon, A.M. 1982. Diagnostic anatomical characters in the Pleurothallidinnae (Orchidaceae). American Journal of Botany 69: 921-38.

Pridgeon, A.M. \& Stern, W.L. 1982. Vegetative anatomy of Mioxanthus (Orchidaceae). Selbyana 7: 55-63.

Pridgeon, A.M. 1994. Systematic leaf anatomy of Caladeniinae (Orchidaceae). Botanical Journal of the Linnean Society 114: $31-48$
Rasmussen, H. 1987. Orchid stomata - structure, differentiation, function, and phylogeny. Pp. 105-138. In: J. Arditti (ed.). Orchid Biology: reviews and perspectives. New York, Cornell University Press.

Royal Botanic Gardens, Kew. 2007. Lista de espécies, genêros e famílias. Disponível em:<http://www.kew.org/wcsp/prepare Checklist.do?checklist=monocots $\% 40 \% 40230180820071502028>$ (Acesso em: 10/08/2007).

Segatto, F.B.; Bisognin, D.A.; Benedetti, M.; Costa, L.C.; Rampelotto, M.V. \& Nicoloso, F.T. 2004. Técnica para o estudo da anatomia da epiderme foliar de batata. Revista Ciência Rural 34: 1597-1601.

Silva, I.V.; Meira, R.M.S.A.; Azevedo, A.A. \& Euclydes, R.M.A. 2006. Estratégias anatômicas foliares de treze espécies de Orchidaceae ocorrentes em um campo de altitude no Parque Estadual da Serra do Brigadeiro (PESB) - MG, Brasil. Acta Botanica Brasilica 20: 741-750.

Sinclair, R. 1990. Water relations in orchids. Pp. 100-119. In: J. Arditti (ed.). Orchid Biology: reviews and perspectives. London, Cornell University.

Singh, H. 1981. Development and organization of stomata in Orchidaceae. Acta Botanica Indica 9: 94-100.

Stern, W.L. 1997. Vegetative anatomy of subtribe Habenariinae (Orchidaceae). Botanical Journal of the Linnean Society 125: 211-227.

Stern, W.L.; Judd, W.S. \& Carlsward, B.S. 2004. Systematic and comparative anatomy of Maxillarieae (Orchidaceae), sans Oncidiinae. Botanical Journal of the Linnean Society 144: 251-274

Stern, W.L.; Morris, M.W.; Judd, W.S.; Pridgeon, A.M. \& Dressler, R.L. 1993. Comparative vegetative anatomy and systematics of Spiranthoideae (Orchidaceae). Botanical Journal of the Linnean Society 113: 161-197.

Suttleworth, F.S. 1997. Orquídeas: guia dos orquidófilos. 7 ed. Rio de Janeiro, Expressão e Cultura.

Uphof, J.C. 1962. Plant hairs. Pp. 1-206. In: K. Linsbauer (ed.). Handbuch Pflanqzenanatomie. Berlin, Gebrüder Borntraeger.

Wilkinson, H.P. 1979. The plant surface (mainly leaf). Pp. 97-165. In: C.R. Metcalfe \& L. Chalk (eds.). Anatomy of the Dicotyledons. $2^{\text {nd }}$ ed. Oxford, Clarendon Press.

Withner, C.L.; Nelson, P.K. \& Wejksnora, P.J. 1974. The anatomy of orchids. Pp. 267-334. In: C.L. Wither (ed.). The Orchids Cientific Studies. New York, John Wiley \& Sons.

Zanengo-Godoy, R. \& Costa, C.G. 2003. Anatomia foliar de quatro espécies do gênero Cattleya Lindl. (Orchidaceae) do Planalto Central Brasileiro. Acta Botanica Brasilica 17: 101-118. 